\title{
The effect of rural-to-urban migration on social capital and common mental disorders: PERU MIGRANT study
}

\author{
Christian Loret de Mola $\cdot$ Sanja Stanojevic • \\ Paulo Ruiz • Robert H. Gilman • Liam Smeeth • \\ J. Jaime Miranda
}

Received: 14 July 2010/Accepted: 23 May 2011 / Published online: 12 June 2011

(c) The Author(s) 2011. This article is published with open access at Springerlink.com

\begin{abstract}
Objective This study aims to investigate whether there are differences in the prevalence of common mental disorders and social capital between migrant and non-migrant groups in Peru.

Methodology The PERU MIGRANT study is a crosssectional study comprising three groups: an urban group from a shanty town in Lima; a rural group from a community in Ayacucho-Peru; and a migrant group originally from Ayacucho currently living in the same urban shanty town. Common mental disorders were assessed using the General Health Questionnaire (GHQ-12), and social capital was assessed using the Short Social Capital Assessment Tool (SASCAT). Poisson regression with robust standard errors was used to estimate prevalence ratios.
\end{abstract}

C. Loret de Mola $(\bowtie) \cdot$ S. Stanojevic · P. Ruiz ·

R. H. Gilman · J. J. Miranda

CRONICAS, Centro de Excelencia en Enfermedades Crónicas,

Universidad Peruana Cayetano Heredia, Av. Armendáriz 497,

2do Piso, Miraflores, Lima 18, Peru

e-mail: christian.loret.de.mola.z@upch.pe

C. Loret de Mola $\cdot$ P. Ruiz $\cdot$ J. J. Miranda

Department of Medicine, School of Medicine,

Universidad Peruana Cayetano Heredia, Lima, Peru

C. Loret de Mola · P. Ruiz

Mental Health Working Group Peru,

Universidad Peruana Cayetano Heredia, Lima, Peru

R. H. Gilman

Department of International Health, Johns Hopkins Bloomberg

School of Public Health, Baltimore, MD, USA

L. Smeeth · J. J. Miranda

Department of Epidemiology and Population Health, London

School of Hygiene and Tropical Medicine, London, UK
Results The overall prevalence of common mental disorders was $39.4 \%$; the highest prevalence was observed in the rural group. Similar patterns were observed for cognitive social capital and structural social capital. However after adjustment for sex, age, family income and education, all but one of the significant relationships was attenuated, suggesting that in this population migration per se does not impact on common mental health disorders or social capital.

Conclusions In the PERU MIGRANT study, we did not observe a difference in the prevalence of common mental disorders, cognitive and structural social capital between migrant and urban groups. This pattern of associations was also similar in rural and urban groups, except that a higher prevalence ratio of structural social capital was observed in the rural group.

Keywords Peru $\cdot$ Migration - Social capital · Mental health

\section{Introduction}

Globally, mental health disorders are ranked the second leading cause of disability-adjusted life years (DALY's) and years of life lived with disabilities; accounting for 12 and $31 \%$ of the total global burden of disease, respectively [1]. In Peru, $30 \%$ of the people are affected by mental health disorders [2] and in Lima, Peru's capital, almost 7\% of the population suffer from depression [3]. Given the magnitude of the disease burden in Peru, there is a need to identify country-specific risk factors, so that appropriate prevention and treatment programs can be developed.

Peru is a culturally diverse country and, during the past 30 years, has experienced large internal migration from 
rural-to-urban areas. During the decades of political violence, between the 1970s and 1990s [4], mass migration occurred throughout the country. During this period thousands died and thousands of families were displaced, mostly from rural areas [5, 6] creating a strong pushing factor to migrate. More than half of these deaths occurred in the Andean department of Ayacucho [6] and most of the migration from Ayacucho was to Lima, Peru's capital [7].

Migration is an important health issue, as changes in the physical and social environment may influence disease patterns [8-10], especially those related to mental health $[9,11,12]$. Despite numerous studies investigating the relationship between migration and mental health $[9,12-$ 15], there is inconsistent evidence as to whether migration is a significant risk factor for mental health disorders. Furthermore, very few studies [16] have studied internal migration within developing countries and their findings might not necessarily apply to the Peruvian context. In the context of increased migration and urbanization in lowand middle-income countries, such questions related to mental health and social capital following migration remain to be addressed.

It is recognized that rural populations have stronger social structures [17] and thus we would expect the process of internal migration, from rural-to-urban settings, to alter social capital and mental health risk. Social capital, defined as the social relationships, bonds and perceptions within societies or groups of people [18], is strongly related to mental health, and some of such evidence was derived from Peru $[18,19]$. A recent literature review in the Latin America and Caribbean region concluded that social capital could have a protective relationship with several health-related areas, and not only mental health. Other areas where social capital has been linked to health include mortality, quality of life, trauma and nutrition [20].

This paper aims to identify the effect of migration on both, social capital and common mental disorders in Peru. Subsequently, we will investigate whether factors such as age at first migration, cumulative time lived in an urban area or percentage of lifetime exposure to an urban environment affect the social capital and common mental disorders.

\section{Methods}

\section{Study design}

The cross-sectional PERU MIGRANT study, conducted in 2007, aimed to establish the effect of migration on cardiovascular risk factors. Details of the study design have been reported in detail elsewhere [21].
Setting

Peru offers a unique opportunity to assess the impact of migration on health. The patterns of migration in Peru changed dramatically during the political violence that occurred in the 1970-1990s period [4], where approximately 70,000 deaths occurred-79\% of them in rural areas - together with high rates of displacement-approximately 120,000 displaced families. Ayacucho, an Andean department, was one of the most severely affected areas during this period of violence-more than $50 \%$ of all deaths occurred in Ayacucho. For the period 1988-1993, $50.7 \%$ of the total emigrants from Ayacucho moved to Lima, making Ayacucho the leading source of migrants to Lima. Given these circumstances, large numbers of people were placed under strong pressure to migrate and it could be suggested that the study population did not represent typical migrants. Also, it is relevant to establish the difference between the concepts of migration from displacement in a political violent situation. First, the selfascertainment of displacement, particularly given the context of terrorism in Peru, constitutes sensitive information. Most migrant participants did not feel comfortable about exposing their reasons to move to Lima. Second, we believe that there is a temporal dimension attached to the definition of displacement in relation to the duration (in months or even years) of these processes. Given the sensitive nature of this information and also, more objectively, given the extended length of period of migration in this study, we do prefer to use the term migration throughout the paper rather than displacement.

The study was composed of three distinct groups: rural, rural-to-urban migrants and urban born dwellers. The village of San Jose de Secce, located in the Santillana District, Huanta Province in Ayacucho was selected as the rural study site. "Las Pampas de San Juan de Miraflores" in Lima, was selected as the urban area. Both urban and ruralurban migrant participants were selected from the Pampas de San Juan de Miraflores area, a periurban shanty town in the south of Lima.

\section{Participants}

A single-stage random sampling method was used in all groups. In the case of San Jose de Secce in Ayacucho, a census was conducted in mid-2007 to identify all adult population permanently living in the area. The sampling frame for the urban group was derived from the local census, conducted in year 2000. All those who reported to have been born in Lima in the 2000 census and currently living permanently in the recorded address were considered eligible for the study. In the case of the rural-to-urban migrant group, the same 2000 census was updated in 2006 
to identify all those who were referred to have been born in the department of Ayacucho and were currently living in Lima.

Individuals aged 30 years old and over, permanently living in their residence, were considered to be eligible. Pregnant women and anyone unable to understand and give written consent were excluded. Language was not considered an exclusion criterion to take part in the study and some of our fieldwork personnel in Lima and all of them in Ayacucho were fluent in Quechua. Participant's selection was stratified by age groups and sex to ensure balanced distribution of covariates. The overall participation rate in the PERU MIGRANT study at enrollment was $73.2 \%$ [21] and of these $75.3 \%$ completed the study $(n=989)$. Detailed participation rates and flowcharts per group have been previously published and are freely available online at http://www.biomedcentral.com/1471-2261/9/23 [21].

\section{Study variables}

The primary exposure was migration from a rural-to-urban environment, defined by study group, i.e., rural, rural-tourban migrant and urban groups. The urban group was defined as individuals who were born in Lima and were permanent residents of the urban site "Las Pampas de San Juan de Miraflores". Migrants were those born in Ayacucho, moved to Lima and were permanent residents of the urban site. The rural group included people born in Ayacucho who were permanent residents of the rural area of the village of San Jose de Secce, located in the Santillana district, Huanta province in Ayacucho, Peru. Of note, the rural group did not consider migrants who returned to their villages.

Social capital was defined as the social relationships, bonds and perceptions within societies or groups of people [18]. In this study, we focused on two components of social capital: first, the structural component which measures the quantity of social relationships inside a community; second, the cognitive component, defined as the person's perception about the quality of this relationship [22]. Social capital was measured using the Short Social Capital Assessment Tool (SASCAT). The SASCAT questionnaire has been previously validated in Peru [19, 22] and includes both, a cognitive and a structural social capital component. In the cognitive component of the SASCAT, a score of three or more, out of four points, was considered "high cognitive social capital" $[19,22]$. The score in the structural social capital (group membership, involvement in citizenship activities and support from individuals in the community) was initially categorized in quartiles and subsequently made into a dichotomous variable with the lowest quartile as the reference.
Common mental disorders (the presence of depression, anxiety and somatic distress) were measured using the General Health Questionnaire (GHQ-12) [23]. This tool was not intended to establish a diagnosis, but was a proxy of the mental health status of the person. The GHQ-12 has not been previously validated in Peru; however after consultation, a group of local experts concluded it was appropriate for this setting. The GHQ-12 score ranges from 0 to 12 points and was dichotomized; a score of 5 or more was considered a positive case based on a previous study conducted in Santiago de Chile [24].

Migration status (rural, migrant, urban) was the primary exposure variable. Sex, age, education level and monthly family income were considered as potential confounders. A secondary analysis was performed where we divided the group of migrants by age of migration $(<12$ years, $>12$ years), years living in an urban area and by percentage of lifetime exposure to an urban area, categorized by quartiles.

\section{Statistical analysis}

Chi-squared tests, including trend analysis, and one-way ANOVA were used for descriptive statistics and univariate analysis. Multivariable analysis was conducted, using generalized linear models (GLM), with the Poisson distribution and robust standard errors to calculate the prevalence ratios (PR). Prevalence ratios were preferred as summary estimates because of the high prevalence observed for the outcomes of interest and, as discussed elsewhere [25], odds ratios would likely yield overestimations in the relationship of interest. Poisson regression with robust standard errors was considered more appropriate, as negative binomial regression models did not converge [25]. Data were analyzed using the statistical program Stata 10 (Stata, College Station, TX, USA).

\section{Results}

The study population is described in Table 1 . A total of 932,911, and 982 measurements were available for GHQ12, cognitive social capital and structural social capital, respectively. The migrant population in this study was an established migrant group; $90 \%$ had migrated to Lima more than 20 years ago. The majority was older than 12 years at the time of migration and approximately $50 \%$ of the group had spent at least half of their lifetime in the urban area (Table 2).

The study groups were similar with respect to sex and age distribution. However, the groups differed in education level and family income (Table 1). The rural group had lower levels of education and lower family income. The urban 
Table 1 Demographic and socioeconomic variables by migration status

\begin{tabular}{|c|c|c|c|c|c|}
\hline & \multicolumn{3}{|l|}{ Group } & \multirow[t]{2}{*}{ Total } & \multirow[t]{2}{*}{$p^{*}$} \\
\hline & Urban & Migrant & Rural & & \\
\hline \multicolumn{6}{|l|}{ Sex } \\
\hline Male & $92(46.2 \%)$ & $281(47.6 \%)$ & $95(47.3 \%)$ & $468(47.3 \%)$ & 0.943 \\
\hline \multicolumn{6}{|l|}{ Age } \\
\hline Mean age & $48.1(46.5-49.8)$ & $47.8(46.8-48.7)$ & $48.3(46.5-50.1)$ & $48(47.2-48.7)$ & $0.84 * *$ \\
\hline \multicolumn{6}{|l|}{ Education level } \\
\hline None & $2(1 \%)$ & $59(10 \%)$ & $68(33.8 \%)$ & $129(13.1 \%)$ & $<0.001$ \\
\hline Incomplete primary & $11(5.6 \%)$ & $124(21.1 \%)$ & $64(31.8 \%)$ & $199(20.2 \%)$ & \\
\hline Complete primary & $23(11.6 \%)$ & $99(16.8 \%)$ & $30(14.9 \%)$ & $152(15.4 \%)$ & \\
\hline Incomplete secondary & $50(25.3 \%)$ & $126(21.4 \%)$ & $16(8 \%)$ & $192(19.5 \%)$ & \\
\hline Complete secondary & $112(56.6 \%)$ & $180(30.6 \%)$ & $23(11.4 \%)$ & $315(31.9 \%)$ & \\
\hline \multicolumn{6}{|l|}{ Family income per month } \\
\hline$\leq \$ 50$ & $2(1 \%)$ & $8(1.4 \%)$ & $109(68.9 \%)$ & $119(13.1 \%)$ & $<0.001$ \\
\hline$\$ 51-150$ & $36(18.7 \%)$ & $143(25.8 \%)$ & $32(20.3 \%)$ & $211(23.3 \%)$ & \\
\hline$\$ 151-250$ & $104(53.9 \%)$ & $292(52.6 \%)$ & $10(6.3 \%)$ & $406(44.8 \%)$ & \\
\hline$\$ 251-350$ & $40(20.7 \%)$ & $82(14.8 \%)$ & $4(2.5 \%)$ & $126(13.9 \%)$ & \\
\hline$\$ 351-450$ & $8(4.2 \%)$ & $26(4.7 \%)$ & $2(1.3 \%)$ & $36(4 \%)$ & \\
\hline$\geq \$ 450$ & $3(1.6 \%)$ & $4(0.7 \%)$ & $1(0.6 \%)$ & $8(0.9 \%)$ & \\
\hline
\end{tabular}

* $p$ value for Chi-square bivariated analysis within groups

** $p$ value using one-way ANOVA

group was mostly likely to complete secondary school (57\%), and the majority earned between $\$ 152$ and 250 per month (54\%). Migrants had similar income patterns, but differed in education from both the urban and rural groups.

The overall prevalence of common mental disorders was high in the PERU MIGRANT population (39.4\%). A trend of increasing prevalence was observed: the urban group had the lowest prevalence (33\%), followed by the migrant group (38\%) and the rural group (49\%) ( $p$ for trend $<0.001)$. Similar trends were also observed for high cognitive social capital (urban $41 \%$, migrants $50 \%$ and rural $74 \%$; $p$ for trend $<0.001)$ and structural social capital above the lowest quartile (urban 62\%, migrants 68\%, and rural $92 \% ; p$ for trend $<0.001$ ).

\section{Common mental disorders}

In the crude model adjusted for age and sex only (Table 3), the rural group had a prevalence ratio for common mental disorders 1.49 (95\% CI 1.09-2.05) times higher than the urban group. However, in the fully adjusted model, the difference was attenuated. The migrant group was not different from the urban group.

\section{Cognitive SASCAT}

Similarly, in the crude analysis the rural group had a prevalence ratio for cognitive social capital 1.80 (95\% CI
Table 2 Patterns of migration

\begin{tabular}{lc}
\hline $\begin{array}{l}\text { Percentage of those living in an urban area } \\
0-25 \%\end{array}$ & $141(25.2 \%)$ \\
$25-50 \%$ & $139(24.9 \%)$ \\
$50-75 \%$ & $142(25.4 \%)$ \\
$75-100 \%$ & $137(24.5)$ \\
Years living in an urban area & \\
$<20$ years & $53(9.5 \%)$ \\
$20-29$ years & $203(36.3 \%)$ \\
$30-39$ years & $169(30.2 \%)$ \\
$>39$ years & $134(24.0 \%)$ \\
Migration age & \\
$<12$ years old & $225(38.5 \%)$ \\
$>12$ years old & $360(61.5 \%)$ \\
\hline
\end{tabular}

1.36-2.37) times higher compared to the urban group; this relationship was also attenuated and not significant in the fully adjusted model. The migrant group had a prevalence ratio of $20 \%$ higher than the urban group, but this difference was not statistically different from the urban group.

\section{Structural SASCAT}

In both the crude and adjusted models, the rural group had a higher structural social capital compared to the urban group, with adjusted PR 1.55 (95\% CI 1.11-2.15). Migrants had a PR $10 \%$ higher than the urban group, but 
Table 3 Crude and adjusted prevalence ratios for GHQ-12, cognitive and structural social capital by migration status

\begin{tabular}{|c|c|c|c|c|c|}
\hline Outcome & Category & Crude $\mathrm{PR}^{\mathrm{a}}$ & $p$ & PR adjusted $^{\mathrm{b}}$ & $p$ \\
\hline \multirow[t]{3}{*}{ GHQ-12 } & Urban $(n=188)$ & 1 & Reference & 1 & Reference \\
\hline & Migrant $(n=544)$ & $1.17(0.88-1.56)$ & 0.27 & $1.07(0.79-1.45)$ & 0.647 \\
\hline & Rural $(n=200)$ & 1.49 (1.09-2.05) & 0.01 & $1.17(0.71-1.94)$ & 0.538 \\
\hline \multirow[t]{3}{*}{ Cognitive SASCAT } & Urban $(n=186)$ & 1 & Reference & 1 & Reference \\
\hline & Migrant $(n=534)$ & $1.20(0.93-1.55)$ & 0.16 & $1.19(0.92-1.55)$ & 0.18 \\
\hline & Rural $(n=191)$ & $1.80(1.36-2.37)$ & $<0.001$ & $1.33(0.87-2.04)$ & 0.192 \\
\hline \multirow[t]{3}{*}{ Structural SASCAT } & Urban $(n=196)$ & 1 & Reference & 1 & Reference \\
\hline & Migrant $(n=585)$ & $1.10(0.90-1.35)$ & 0.34 & $1.12(0.90-1.38)$ & 0.31 \\
\hline & Rural $(n=201)$ & $1.49(1.19-1.88)$ & $<0.001$ & $1.55(1.11-2.15)$ & 0.01 \\
\hline
\end{tabular}

${ }^{a}$ Crude analysis included adjustment by age and sex

b Model adjusted by age, sex, family income and education level

this was not statistically significant in either the crude or adjusted model.

\section{Pattern of migration}

The age of migration, number of years living in an urban area and the percentage of lifetime exposure to an urban area did not affect the interpretation of the results for any of the three outcomes (data not shown).

\section{Discussion}

\section{Main findings}

The PERU MIGRANT study is the first study in Peru to evaluate the relationship between migration and common mental disorders and social capital. We did not find differences in the prevalence of common mental disorders, cognitive social capital or structural social capital between migrant and urban groups. Compared with the urban group, the rural group had higher prevalence of common mental disorders and cognitive social capital; however, this relationship was fully attenuated in the adjusted models, suggesting that education and income may explain part or most of this relationship. On the other hand, also comparing rural and urban groups, the structural social capital maintained this association in the adjusted model, suggesting that the rural region may have a better social structure.

\section{Comparison with other studies}

The high levels of social capital observed in the rural setting are consistent with other reports addressing social capital in Peru [17]. Following the period of political violence, social capital in rural areas has largely been re- constructed as a result of local social support programs [17]. The previous rural social networks, destroyed by terrorism, were replaced with community organizations, women's groups, residents' associations, self-defense committees and individual networks [17].

The lower levels of social networks observed in migrants in this study could reflect the length of residence in urban areas. Given their rural origin, in a context where strong social networks were present, we would expect that migrants had initially similar strong interactions through social networks as many of the settlers to Pampas originated from the same rural areas. However, over time and paired with sustained urban exposure, it is possible that these networks may have been reduced or dissolved. This may explain why differences between migrant and urban group in terms of common mental disorders and levels of social capital were not observed.

Our results concerning common mental disorders are consistent with those of a recent meta-analysis [15], which concluded there was no relationship between migration and common mental disorders. The limited number of studies that found an association between migration and common mental disorders was based on international migration and settings different from Peru [12, 26-28], including a recent study of Ecuadorian migrants living in Spain [29]. This discordance may be due to the heterogeneity of the definition of "migrant", including labor migrants and/or refugees, and the use of different tools to measure common mental disorders. Of interest, however, is that most of the international migration studies tend to place migrant population as disadvantaged in terms of their mental health compared to local non-migrant residents [14]. The evidence with regard to rural-to-urban migration seems to indicate the opposite, indicating that the migration process is a much more complex phenomena. The results from a recent study focusing on rural-to-urban migration of 
Chinese migrant workers [16] suggest that migrants are better off than their rural counterparts in terms of mental health. A more recent publication of the same group, focusing on the general population of Beijing, suggests a possible deteriorative effect of the migratory experience on mental health status [30]. Our study provided similar results-of a gradient of increasing rates of common mental disorders from urban to migrant to rural groups-in the exploratory analyses but such estimates were not confirmed in the multivariable regression models. Such attenuation in the estimates also occurred in the Chinesebased studies [16, 30].

A previous work carried out in the same rural area of Ayacucho has focused on post-traumatic stress disorders. Tremblay et al. [31], who also used the GHQ-12 as an exploratory tool, found a $72 \%$ prevalence of common mental disorders. Their study, however, used a lower cutoff, GHQ-12 >2 instead of 5 as used in our study and was conducted in a much younger population, $>15$ years of age, thus making it difficult to compare their estimates with the prevalence obtained in this study [31]. In this study, we also observed a very high prevalence of common mental disorders, particularly in the rural group. Although our mental health tools were not validated in this population, we used a conservative cutoff of common mental disorders to avoid over-estimating the prevalence. However, the high prevalence of mental health disorders observed are in line with those reported in earlier studies evaluating mental health in the same region of Peru [4, 31] suggesting that rural residents in Ayacucho have a high and underdiagnosed prevalence of common mental health disorders. As this tool was not designed to investigate mental health in rural residents, further studies are needed to validate the GHQ and to evaluate the prevalence of mental health in rural populations.

\section{Strengths and limitations}

This study benefits from having long-term residents in a rural area, long-term residents in an urban area and those who migrated from that specific rural area to a common urban area. The availability of these groups enables a more appropriate comparison of migrant populations.

Some of the limitations of our study are noteworthy. As with any migration study, selection bias does introduce additional challenges in the interpretation of the results of such studies [32-34]. Given Peru's political circumstances, especially in rural areas [7], a large number of people were placed under strong pressures to migrate and it could be suggested that the study population does not represent typical migrants. In a separate analysis of the Peru MIGRANT dataset [35], using the instrumental variable method and propensity score matching, no differences were observed between the migrant and the rural groups with respect to observable socioeconomic factors and unobserved characteristics. These results suggest that selection bias did not influence our study findings, and thus the observations reported contributes to expand our knowledge of the impacts of rural-to-urban migration in low and middle income settings.

Being a cross-sectional study, any causal relationship between migration, common mental disorders and social capital cannot be inferred. In addition, since the study was not powered to investigate subgroup differences, we are less confident regarding the lack of association between length of migration or exposure to the urban environment and mental health and social capital. The measurement of social capital before migration would have been useful to address the level of impact of trauma on migration; however due to the cross-sectional nature of the study this information was not available.

\section{Conclusions and implications}

In this secondary analysis of the PERU MIGRANT study, we did not find differences in the prevalence of common mental disorders or cognitive social capital between migrant and urban groups. In the case of the estimates attenuated in fully adjusted models, the results suggest that education and income may explain the differences between rural and urban residents in Peru, with the exception of structural social capital that was higher in the rural group. In light of these results, future studies in Peru should aim to verify these findings in different migrant groups and extend them to younger populations using, if possible, different tools to measure mental health.

Acknowledgments This work was funded in whole by a Wellcome Trust Masters Research Training Fellowship and a Wellcome Trust PhD Studentship to JJM (GR074833MA). LS was supported by a Wellcome Trust Senior Research Fellowship in Clinical Science. The CRONICAS Center of Excellence in Chronic Diseases at UPCH is funded by the National Heart, Lung and Blood Institute, National Institutes of Health, Department of Health and Human Services, under contract No. HHSN268200900033C. We extend our special gratitude to various colleagues at the Universidad Peruana Cayetano Heredia and A.B. PRISMA in Lima, Peru and several others in the UK, as well as to the staff and the team of fieldworkers who contributed to different parts of this study. Most importantly, our sincere gratitude is extended to the people who agreed to take part in the study and to Juan Francisco Chiroque, Candice Romero and Lilia Cabrera who coordinated the fieldwork phase of this study. We would like to thank Dr. Mary De Silva for constructive review of an earlier draft of this manuscript, and Andres Lescano, Cecilia Montes and Kelika Konda for statistical advice and comments.

Conflict of interest The authors declare that they have no competing interests. 
Open Access This article is distributed under the terms of the Creative Commons Attribution Noncommercial License which permits any noncommercial use, distribution, and reproduction in any medium, provided the original author(s) and source are credited.

\section{References}

1. WHO (2001) The World Health report, 2001. Mental health: new understanding, new hope. Geneva

2. PAHO (2007) Salud en las Americas: Peru. Salud en las Americas

3. Saavedra J (2002) Estudio Epidemiológico Metropolitano en Salud Mental. Informe General. Anales de Salud Mental XVIII

4. Pedersen D, Tremblay J, Errazuriz C, Gamarra J (2008) The sequelae of political violence: assessing trauma, suffering and dislocation in the Peruvian highlands. Soc Sci Med 67:205-217

5. Coral I (1994) Desplazamiento por violencia politica en el Peru, 1980-1992. Instituto de Estudios Peruanos, Lima

6. Comisión de la Verdad y Reconciliación (2003) Informe Final de la Comisión de la Verdad y Reconciliación (Peruvian Truth and Reconciliation Comision's Final Report). Comisión de la Verdad y Reconciliación, Lima. Available at: http://www.cverdad.org.pe/ ifinal/index.php

7. INEI (2009) Las Migraciones Internas en el Peru: 1993-2007. Instituto Nacional de Estadistica e Informatica (INEI), Lima

8. Bhugra D (2005) Cultural identities and cultural congruency: a new model for evaluating mental distress in immigrants. Acta Psychiatr Scand 111:84-93

9. Murphy HB (1977) Migration, culture and mental health. Psychol Med 7:677-684

10. Nicolas G, Desilva AM, Subrebost KL, Breland-Noble A, Gonzalez-Eastep D et al (2007) Expression and treatment of depression among Haitian immigrant women in the United States: clinical observations. Am J Psychother 61:83-98

11. Fazel M, Wheeler J, Danesh J (2005) Prevalence of serious mental disorder in 7000 refugees resettled in western countries: a systematic review. Lancet 365:1309-1314

12. Ryan L, Leavey G, Golden A, Blizard R, King M (2006) Depression in Irish migrants living in London: case-control study. Br J Psychiatry 188:560-566

13. Bhugra D (2003) Migration and depression. Acta Psychiatr Scand Suppl:67-72

14. Missinne S, Bracke P (2010) Depressive symptoms among immigrants and ethnic minorities: a population based study in 23 European countries. Soc Psychiatry Psychiatr Epidemiol

15. Swinnen SG, Selten JP (2007) Mood disorders and migration: meta-analysis. Br J Psychiatry 190:6-10

16. Li L, Wang HM, Ye XJ, Jiang MM, Lou QY et al (2007) The mental health status of Chinese rural-urban migrant workers: comparison with permanent urban and rural dwellers. Soc Psychiatry Psychiatr Epidemiol 42:716-722

17. De Silva MJ, Harpham T, Huttly SR, Bartolini R, Penny ME (2007) Understanding sources and types of social capital in Peru. Community Dev J 42:19-33

18. De Silva MJ, McKenzie K, Harpham T, Huttly SR (2005) Social capital and mental illness: a systematic review. J Epidemiol Community Health 59:619-627
19. Silva De, Huttly SR, Harpham T, Kenward MG (2007) Social capital and mental health: a comparative analysis of four low income countries. Soc Sci Med 64:5-20

20. Kripper CE, Sapag JC (2009) Capital social y salud en América Latina y el Caribe: una revisión sistemática. Revista Panamericana de Salud Publica 25:162-170

21. Miranda JJ, Gilman RH, Garcia HH, Smeeth L (2009) The effect on cardiovascular risk factors of migration from rural to urban areas in Peru: PERU MIGRANT Study. BMC Cardiovasc Disord 9:23

22. De Silva MJ, Harpham T, Tuan T, Bartolini R, Penny ME et al (2006) Psychometric and cognitive validation of a social capital measurement tool in Peru and Vietnam. Soc Sci Med 62:941-953

23. Goldberg DP, Gater R, Sartorius N, Ustun TB, Piccinelli M et al (1997) The validity of two versions of the GHQ in the WHO study of mental illness in general health care. Psychol Med 27:191-197

24. Araya R, Wynn R, Lewis G (1992) Comparison of two selfadministered psychiatric questionnaires (GHQ-12 and SRQ-20) in primary care in Chile. Soc Psychiatry Psychiatr Epidemiol $27: 168-173$

25. Barros AJ, Hirakata VN (2003) Alternatives for logistic regression in cross-sectional studies: an empirical comparison of models that directly estimate the prevalence ratio. BMC Med Res Methodol 3:21

26. Lai DW (2005) Prevalence and correlates of depressive symptoms in older Taiwanese immigrants in Canada. J Chin Med Assoc 68:118-125

27. Merbach M, Wittig U, Brahler E (2008) Anxiety and depression by Polish and Vietnamese migrants in Leipzig depending on their adaptation process. Psychother Psychosom Med Psychol 58:146-154

28. Romans S, Cohen M, Forte T (2010) Rates of depression and anxiety in urban and rural Canada. Soc Psychiatry Psychiatr Epidemiol

29. Del Amo J, Jarrin I, Garcia-Fulgueiras A, Ibanez-Rojo V, Alvarez D et al. (2010) Mental health in Ecuadorian migrants from a population-based survey: the importance of social determinants and gender roles. Soc Psychiatry Psychiatr Epidemiol

30. Li X, Stanton B, Fang X, Xiong Q, Yu S et al (2009) Mental health symptoms among rural-to-urban migrants in China: a comparison with their urban and rural counterparts. World Health Popul 11:24-38

31. Tremblay J, Pedersen D, Errazuriz C (2009) Assessing mental health outcomes of political violence and civil unrest in Peru. Int J Soc Psychiatry 55:449-463

32. Abraido-Lanza AF, Dohrenwend BP, Ng-Mak DS, Turner JB (1999) The Latino mortality paradox: a test of the "salmon bias" and healthy migrant hypotheses. Am J Public Health 89:1543-1548

33. Razum O, Twardella D (2002) Time travel with Oliver Twisttowards an explanation for a paradoxically low mortality among recent immigrants. Trop Med Int Health 7:4-10

34. Razum O (2006) Commentary: of salmon and time travellersmusing on the mystery of migrant mortality. Int $\mathrm{J}$ Epidemiol 35:919-921

35. Miranda JJ (2009) Migration from rural to urban Areas in Peru: impact on health outcomes. Georgia State University, Atlanta. Available at: http://aysps.gsu.edu/ECON_MA_MonteroJJ.pdf 